\title{
Dermoscopic Findings and Their Therapeutic Implications in Trichostasis Spinulosa: A Retrospective Study of 306 Patients
}

\author{
Awatef Kelati Niema Aqil Fatima Zahra Mernissi \\ Department of Dermatology, University Hospital Hassan II, Fez, Morocco
}

\section{Keywords}

Trichostasis spinulosa $\cdot$ Dermoscopy $\cdot$ New findings

\begin{abstract}
Background: Data about the contribution and the implications of dermoscopy in trichostasis spinulosa (TS) are lacking in the literature. Objective: To describe dermoscopic features of TS in a large sample of patients and to correlate dermoscopy with clinical characteristics of the patients and therapeutic responses to medical treatments. Methods: A descriptive study was conducted (from October 2015 to June 2016) at the Department of Dermatology of Fez in Morocco. Dermoscopic signs were divided into signs of hair retention (SHR) and follicular keratosis (FK). Results: SHR was severe in $8.8 \%$ and minimal in $40.5 \%$ of all cases. Vellus hairs were observed in $81.6 \%$ of all cases and hair tufts were described in $48.7 \%$. Dermoscopic blackhead-like structures $(\mathrm{DBH})$ were found in $53.9 \%$ of all cases. FK was observed as orange-yellowish keratotic plugs in $92.7 \%$ of all cases. Therapeutic demand was significantly related to female gender $(p=0.002)$ and recurrences after medical treatment ( $p=$ 0.004). Complete improvement after medical treatment was only described in patients with $\mathrm{DBH}$ and minimal SHR ( $p=$
\end{abstract}

(c) 2018 S. Karger AG, Basel

E-Mail karger@karger.com

www.karger.com/sad
0.001). Conclusion: Dermoscopy not only increases the accuracy of the clinical diagnosis in TS, but a new description of dermoscopic classification has also been proposed leading to therapeutic implications.

(c) 2018 S. Karger AG, Basel

\section{Introduction}

Trichostasis spinulosa (TS) is a relatively common but underdiagnosed follicular disorder, it is a congenital dysplasia of the hair follicles with an abnormal angulation between the isthmus and the infundibulum and an entrapment of up to 50 small vellus hairs (VH) in a hair follicle $[1,2]$. Facial TS is characterized by hyperkeratosis of a dilated hair follicle with retention of multiple telogen $\mathrm{VH}$, it appears clinically as asymptomatic blackhead comedo-like lesions on the tip of the nose, the alae of the nose, and the cheeks [1].

The diagnosis of TS may be difficult using only naked-eye examination. Differential diagnosis of facial lesions includes comedogenic acne, keratosis pilaris, eruptive VH cysts, Favre-Racouchot syndrome, and dilated pores in the elderly (Fig. 1). Microscopic examina- 
Table 1. Descriptive analysis of the 306 patients

\begin{tabular}{|c|c|c|c|}
\hline Variables & All & $\begin{array}{l}\text { Male } \\
\text { patients }\end{array}$ & $\begin{array}{l}\text { Female } \\
\text { patients }\end{array}$ \\
\hline Gender & 306 & $95(31.1 \%)$ & $211(68.9 \%)$ \\
\hline Family history of trichostasis spinulosa & $51(16.7 \%)$ & $7(7.3 \%)$ & $44(20.8 \%)$ \\
\hline \multicolumn{4}{|l|}{ Medical treatments used before } \\
\hline Moisturizers & $211(68.9 \%)$ & 0 & $211(68.9 \%)$ \\
\hline Retinoids & $26(8.5 \%)$ & 0 & $26(8.5 \%)$ \\
\hline Comedo cleansing & $26(8.5 \%)$ & 0 & $26(8.5 \%)$ \\
\hline \multicolumn{4}{|l|}{ Clinical signs } \\
\hline Blackheads & $215(70.3 \%)$ & $56(59 \%)$ & $159(75.3 \%)$ \\
\hline Dilated pores & $71(23.2 \%)$ & $31(32.6 \%)$ & $40(18.9 \%)$ \\
\hline Blackheads and visible hairs & $12(3.9 \%)$ & $5(5.2 \%)$ & $7(3.3 \%)$ \\
\hline Blackheads with dilated pores & $4(1.3 \%)$ & $3(3.1 \%)$ & $1(0.47 \%)$ \\
\hline \multicolumn{4}{|l|}{ Location of trichostasis spinulosa } \\
\hline Nose & $170(55.3 \%)$ & $53(55.7 \%)$ & $117(55.4 \%)$ \\
\hline Nose and cheeks & $104(33.8 \%)$ & $33(34.7 \%)$ & $71(33.6 \%)$ \\
\hline Alae of the nose & $17(5.6 \%)$ & $4(4.2 \%)$ & $13(6.1 \%)$ \\
\hline Whole face & $15(4.9 \%)$ & $5(5.2 \%)$ & $10(4.7 \%)$ \\
\hline \multicolumn{4}{|l|}{ Signs of hair retention } \\
\hline Vellus hairs surrounded by follicular plugs & $250(81.6 \%)$ & $73(76.8 \%)$ & $177(83.8 \%)$ \\
\hline Dermoscopic blackhead-like structures & $165(53.9 \%)$ & $45(47.3 \%)$ & $120(56.8 \%)$ \\
\hline Hair tufts & $149(48.7 \%)$ & $46(48.4 \%)$ & $103(48.8 \%)$ \\
\hline \multicolumn{4}{|l|}{ Degree of signs of hair retention } \\
\hline Severe & $27(8.8 \%)$ & $10(10.5 \%)$ & $17(8.05 \%)$ \\
\hline Moderate & $155(50.6 \%)$ & $52(54.7 \%)$ & $103(48.8 \%)$ \\
\hline Minimal & $124(40.5 \%)$ & $37(38.9 \%)$ & $87(41.2 \%)$ \\
\hline Follicular keratosis with minimal hair retention & $284(92.7 \%)$ & $85(89.4 \%)$ & $199(94.3 \%)$ \\
\hline \multicolumn{4}{|c|}{ Degree of follicular keratosis with minimal hair retention } \\
\hline Severe & $98(32 \%)$ & $26(27.3 \%)$ & $72(34.1 \%)$ \\
\hline Moderate & $83(27 \%)$ & $23(24.2 \%)$ & $60(28.4 \%)$ \\
\hline Minimal & $124(40.5 \%)$ & $47(49.4 \%)$ & $77(36.4 \%)$ \\
\hline
\end{tabular}

tion of few spines shows fine retained telogen $\mathrm{VH}$ embedded in keratinaceous debris [2]. Skin biopsy of the contents of black papules shows findings of dilated hair follicle containing multiple $\mathrm{VH}$ with mild inflammation. Also, TS should be considered in the differential diagnosis when treatment-resistant comedo-like lesions are seen [3]. Recently, dermoscopy has been reported to be the most helpful, easy, and noninvasive tool to diagnose TS $[1,4]$.

This study aimed to describe the dermoscopic features of TS in a large sample of patients, to assess the severity of this condition by evaluating the abundance of hair abnormalities per dermoscopic field, and to correlate dermoscopic features with clinical characteristics of patients and therapeutic responses to medical treatments.

\section{Methods}

Study Design

A descriptive retrospective study was conducted during a period of 10 months, from October 2015 to June 2016, at the Department of Dermatology, University Hospital Hassan II of Fez, Morocco.

\section{Participants}

Patients having facial TS were included in this study. Body lesions of TS were not evaluated. The diagnosis of TS was confirmed based on dermoscopic findings as one or tuft of $\mathrm{VH}$ with varying diameters emerging from dilated follicular openings, with keratotic plugs filling the follicular openings and surrounding $\mathrm{VH}$ [1].

\section{Outcome Measures}

Dermoscopic images were documented with a digital camera (DermLite or Fotofinder) without polarized light and without immersion. The dermoscopic findings were divided into 2 categories: follicular keratosis (FK) with minimal hair retention and 
Fig. 1. Differential diagnosis of facial trichostasis spinulosa. a Favre-Racouchot syndrome with dermoscopic findings of dilated empty follicular openings surrounded by a blue-grayish halo. b Comedogenic acne with dermoscopic findings of prominent whitish plugs inside the follicular openings. c Dilated pores with dermoscopic findings of dilated follicular openings of different sizes filled with yellow-whitish plugs. d Eruptive vellus hair cysts, dermoscopy shows well-defined, circular, whitish structures. (All of these images were taken using a Fotofinder dermoscope with a $20 \times$ magnification.)
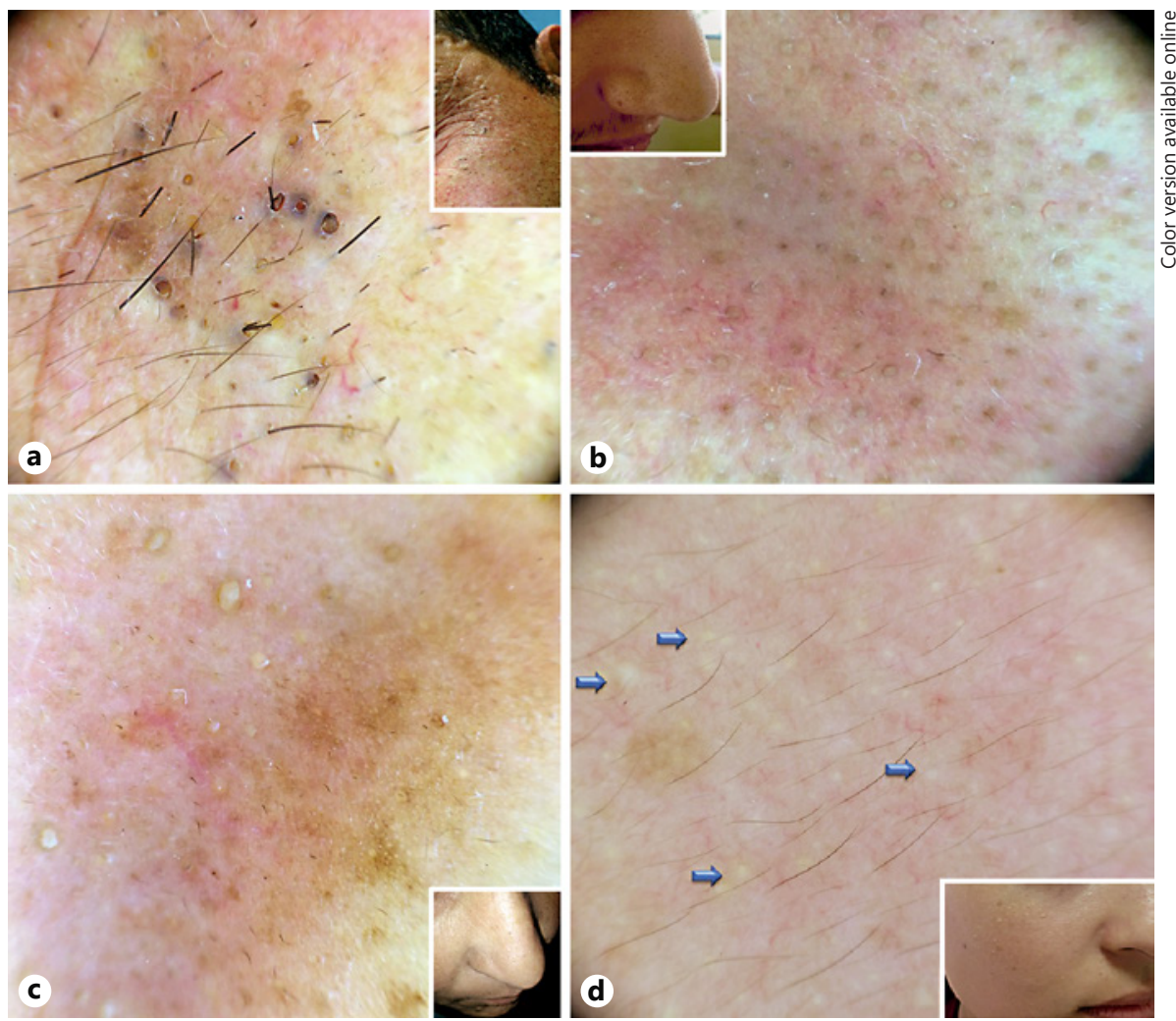

signs of hair retention (SHR) as $\mathrm{VH}$ surrounded by follicular plugs, hair tuft (HT), and dermoscopic blackhead-like structures $(\mathrm{DBH})$. The severity of hair abnormalities was assessed per dermoscopic field. It was considered to be minimal if $\leq 20$, to be moderate between 20 and 50 , and to be severe if $\geq 50$. The clinical and dermoscopic data were analyzed and evaluated by two independent dermoscopists experienced in dermoscopy at our department.

\section{Statistical Analysis}

Data extraction was performed using Excel software. The data were then analyzed using IBM SPSS Statistics software version 20. Descriptive variables were expressed as means and percentages. In the univariate analysis, the $\chi^{2}$ test was used to compare these percentages. A $p$ value $<0.05$ was considered statistically significant.

\section{Results}

A total of 306 patients (211 females and 95 males) with TS were enrolled in the study. The average age of our patients was 41.6 years (15-79 years). A family history of TS was observed in $16.7 \%$ of all patients, this percentage was higher in females (20.8\%). Clinical signs of TS in these patients were blackheads in $70.3 \%$ of all cases, dilated pores in $23.2 \%$ with a predominance of this sign in males (32.6 vs. $18.9 \%$ in females), blackheads and visible hairs in $3.9 \%$, and blackheads with dilated pores in $1.3 \%$ (Table 1 ). The location of the TS was the nose in $55.3 \%$ of all cases, the nose and the cheeks in $33.8 \%$, the alae of the nose in $5.6 \%$, and the whole face in $4.9 \%$ (Table 1). Therapeutic demand was described in $8.5 \%$ of all cases after incomplete response to retinoids and comedo cleansing. 91.5\% of all patients consulted our department for other dermatologic reasons.

SHR were described as severe in $8.8 \%$ and minimal in $40.5 \%$ of all cases (Table 1). VH surrounded by follicular plugs was the most frequent type of SHR (81.6\% of all cases), DBH was noticed in 53.9\%, and HT was observed in $48.7 \%$. FK with minimal hair retention was described as orange-yellowish keratotic plugs in $92.7 \%$ of all cases These follicular abnormalities were severe in 32\%, moderate in $27 \%$, and minimal in $40.5 \%$ of all cases (Fig. 1-3).

The severity of hair retention in TS was significantly related to the presence of a family history of the disease $(p=0.01)$. No relationship was noticed between specific dermoscopic findings and age or gender. However, the use of medical treatment and therapeutic demand were significantly related to female gender $(p=0.002)$. Therapeu- 
Fig. 2. Trichostasis spinulosa dermoscopy. a Severe degree of hair retention: dermoscopic blackheads. b Moderate follicular keratosis. c Severe degree of hair retention: vellus hairs. d Important follicular keratosis. (a, c, d Images were taken using a Fotofinder dermoscope, and $\mathbf{b}$ was taken using a DermLight dermoscope with a $20 \times$ magnification.)

Fig. 3. Trichostasis spinulosa dermoscopy. a, c Severe degree of hair retention. b Moderate degree of hair retention. d Minimal degree of hair retention. Tuft hairs (orange arrows), vellus hairs (green arrows), dermoscopic blackhead-like structures (blue arrows). (All of these images were taken using a Fotofinder dermoscope with a $20 \times$ magnification.)
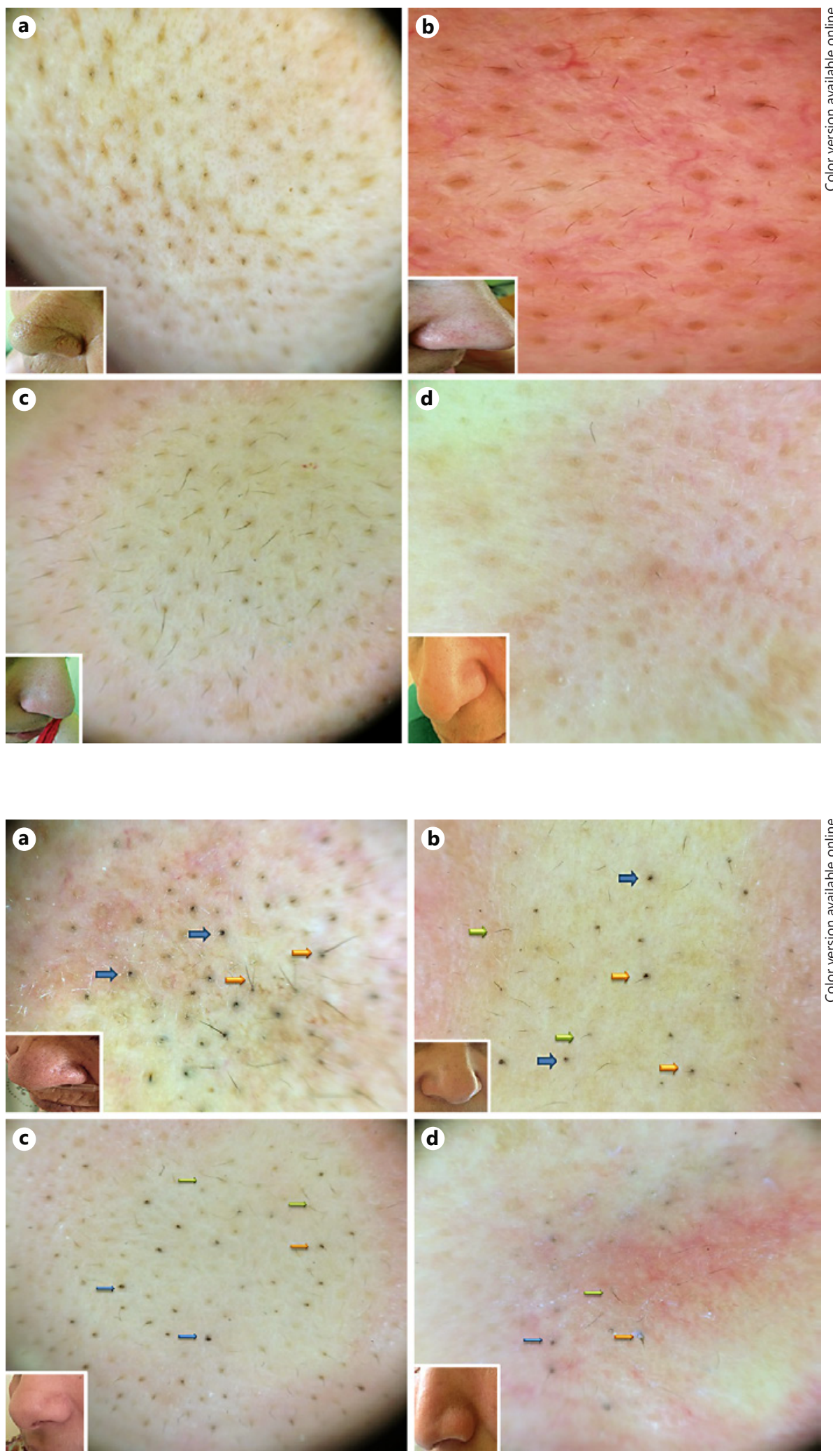
tic demand was also related to an incomplete improvement with recurrences after medical treatment with keratolytics and retinoids or comedo cleansing $(p=0.004)$.

Complete improvement after medical treatments was only described in patients with DBH and follicular keratosis with minimal SHR $(p=0.001)$. Laser treatment was planned for patients having other dermoscopic abnormalities after incomplete improvement with medical treatment.

\section{Discussion}

There are a few reports in the literature that were interested in the contribution and the implications of dermoscopy in facial TS, most of them are case reports [4-6]. The diagnosis of TS may be based only on dermoscopic findings of tufts of $\mathrm{VH}$ with varying diameters emerging from dilated follicular openings [4] and FK [1]. Microscopic and histologic examination does not add any other findings. In addition to what has been reported, this is - to the best of our knowledge - the first study that investigated the role of dermoscopy in assessing the extent and the severity of the disease based on the density or the number of dermoscopic features per dermoscopic field. The disease's severity was significantly related to a family history of the disease, with no correlation with therapeutic choices.

TS is not a morbid condition, but it may pose a cosmetic problem in young female patients, as we noticed in the present study. The disease usually follows a chronic refractory course and tends to reappear after discontinuation of treatment $[2,3]$. The spines of impacted hairs can be removed by tweezing, by pressure expression [7], or keratolytics [2]. Hair removal lasers, using an $800-\mathrm{nm}$ pulse diode, or long- and short-pulsed 755-nm alexandrite lasers have been reported to be effective [8].
A classification of the dermoscopic signs into SHR and FK - as we did in our study - would be of great help in choosing the best treatment and in selecting, for example, medical treatments or pressure expression for patients with $\mathrm{DBH}$ and FK independently of the extent of the dermoscopic signs. DBH or dermoscopic black comedones are not the same as black dots in trichoscopy. The latter is caused by fractured hairs at the level of skin emergence [9], while the former are follicular openings filled with oxidized melanin and sebum, which are easily extracted by pressure expression.

Although our study did not investigate the utility of hair removal laser for TS, it may be the only option for patients with SHR such as VH and HT after other treatment has failed. Further studies are needed to confirm these results.

\section{Conclusion}

This study described new observations in the dermoscopy of TS. These will not only increase the accuracy of the clinical diagnosis, but they will also be of great help in assessing this condition's severity and therapeutic implications.

\section{Statement of Ethics}

This study was approved by our local Ethics Committee. All subjects were informed of the conditions related to the study and gave their informed consent.

\section{Disclosure Statement}

The authors have no conflicts of interest to disclose.

\section{References}

1 Panchaprateep R, Tanus A, Tosti A: Clinical, dermoscopic, and histopathologic features of body hair disorders. J Am Acad Dermatol 2015;72:890-900

2 Sardana K: Follicular disorders of the face. Clin Dermatol 2014;32:839-872.

-3 Gündüz Ö, Aytekin A: Trichostasis spinulosa confirmed by standard skin surface biopsy. Int J Trichology 2012;4:273.
4 Naveen K, Shetty S: Trichostasis spinulosa: an overlooked entity. Indian Dermatol Online J 2014;5:132.

5 Amazan E, Milpied B, Droitcourt C, Taïeb A: Trichostasis spinulosa : une cause méconnue de prurit et intérêt du dermoscope. Ann Dermatol Venereol 2011;138:141.

6 Pozo L, Bowling J, Perrett CM, Bull R, DiazCano SJ: Dermoscopy of trichostasis spinulosa. Arch Dermatol 2008; 144 .

-7 Aşkin Ü, Seçkin D: Two cases of trichostasis spinulosa treated with cyanoacrylic adhesive. Eur J Dermatol 2014;24:416-417.
Dermoscopic Findings and Their Therapeutic Implications in TS
Skin Appendage Disord 2018;4:291-295 DOI: $10.1159 / 000486541$
8 Badawi A, Kashmar M: Treatment of trichostasis spinulosa with 0.5 -millisecond pulsed $755-\mathrm{nm}$ alexandrite laser. Lasers Med Sci 2011;26:825-829.

9 Chagas FSC, Donati A, Soares IID, Valente NS, Romiti R: Trichostasis spinulosa of the scalp mimicking Alopecia areata black dots. An Bras Dermatol 2014;89:685-687. 